\title{
O SIGNIFICADO CONSTITUCIONAL DA JUSTA INDENIZAÇÃO EXPROPRIATÓRIA
}

\author{
THE JUST COMPENSATION CONSTITUTIONAL MEANING
}

\begin{abstract}
Jessica Acocella ${ }^{1}$
RESUMO: O instituto da desapropriação, sem dúvida, gera, até os dias de hoje, inegáveis benefícios para a coletividade, viabilizando, por exemplo, grandes obras públicas e os cada vez mais imprescindíveis projetos de infraestrutura, sobretudo urbana. Não há, portanto, como se fazer uma defesa absoluta da propriedade e uma crítica ingênua à atividade estatal expropriatória, como se dela pudesse definitivamente abrir mão a Administração Pública. Mas, por outro lado, não é possível negar que o modelo de desapropriação, tal como praticado na atualidade, está em crise, sobretudo em razão da incompatibilidade de importantes normas do regime jurídico até hoje vigente com a ordem constitucional. Essa situação acaba, assim, por demandar, na ausência de uma ampla reforma legal da matéria, um maior esforço de interpretação da legislação vigente, que exigirá, em primeiro lugar, sua releitura à luz dos valores e ditames da Constituição de 1988. Por essas razões, no presente artigo, foram propostas algumas reflexões acerca do instituto expropriatório, notadamente no que diz respeito ao significado da exigência constitucional de que seja a indenização justa, a ensejar, dentre outros requisitos, a legitimação do uso da força que lhe é inerente, considerando-se o presente estágio de desenvolvimento do nosso Estado democrático de Direito.
\end{abstract}

Palavras-chave: Desapropriação. Indenização justa e prévia. Significado constitucional.

ABSTRACT: There's no doubt that the eminent domain power of the State is usefull until nowadays to benefit in many important ways the community, making it posible, for example, large public works or infrastructure projects increasingky essential, particularly urban ones. It's not posible, then, to make an absolute property defense and a naïve critical to the eminent domain power, as if it were posible to the State to abandon its use. But, on the other hand, we can't deny that the model of expropriation, such as it is still exercised, is in crisis, specially because of the inconsistency between some relevant rules of the actual takings regime and our present constitutional system. For this reason, and in the absence of a comprehensive law reform, it is required a bigger effort to interpret the actual takings law, what implies, firstly, rereading it in the light of our present Constitution values and commands. That's why we propose, in this study, to reflect about the eminent domain power, mainly about the meaning of the just compensation constitutional requirement, that is able to legitimate the use of its

\footnotetext{
${ }^{1}$ Advogada do BNDES e mestre em Direito Público pela UERJ. E-mail para contato:jessacocella@yahoo.com.br.
}

Versão em português recebida em 11/06/2014, aceita em 24/11/2014, e autorizada para publicação em 29/06/2015 


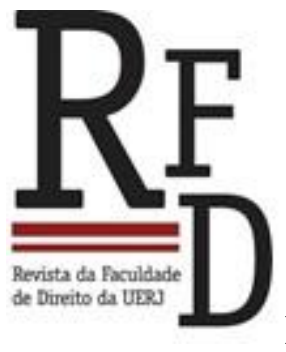

REVISTA DA FACULDADE DE DIREITO DA UERJ- RFD, N. 27, 2015

inherent force, considering the actual stage of our Democractic State of Law.

Keyword: Expropiation. Eminent domain power. Just compensation meaning.

\section{INTRODUÇÃO}

O instituto da desapropriação, sem dúvida, gera, até os dias de hoje, inegáveis benefícios para a coletividade, viabilizando, por exemplo, grandes obras públicas e os cada vez mais imprescindíveis projetos de infraestrutura, sobretudo urbana. Sem essa prerrogativa estatal, seria impensável deixar ao arbítrio privado o fornecimento, a seu critério, dos mais variados bens de interesse coletivo, necessários tanto para o desenvolvimento como para o bem-estar da sociedade.

Não há, portanto, como se fazer uma defesa absoluta da propriedade e uma crítica ingênua à atividade estatal expropriatória, como se dela pudesse definitivamente abrir mão a Administração Pública. Ao contrário, a desapropriação, de limite negativo do direito de propriedade, tem se convertido em um instrumento positivo colocado à disposição do Poder Público para o cumprimento de suas funções de ordenação espacial e conformação da sociedade aos crescentes imperativos de justiça social.

Mas, por outro lado, não é possível negar que o modelo de desapropriação - um dos temas, podemos dizer, mais clássicos do nosso Direito Administrativo -, tal como praticado na atualidade, está em crise, sobretudo em razão da incompatibilidade de importantes normas do regime jurídico até hoje vigente com a atual ordem constitucional. Essa crise manifesta-se, por exemplo, pela demora no pagamento da indenização devida ao particular afetado, pela ainda persistente apropriação pública, em alguns casos, da propriedade privada, em desrespeito às garantias do devido processo legal e da justa e prévia indenização em dinheiro.

Essa situação acaba por demandar, na ausência de uma ampla reforma do tratamento normativo do instituto (o que se torna, aliás, cada vez mais premente), um esforço maior de interpretação da legislação vigente, que exigirá, em primeiro lugar, sua releitura à luz dos valores e ditames da Constituição de 1988, principalmente tendo em vista que o regime jurídico até hoje aplicável é, predominantemente, anterior à atual ordem constitucional.

Por essas razões, neste artigo, serão propostas algumas reflexões acerca da matéria, Versão em português recebida em 11/06/2014, aceita em 24/11/2014, e autorizada para publicação em 29/06/2015 


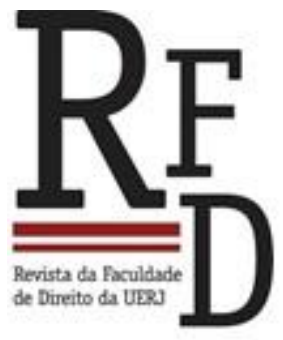

REVISTA DA FACULDADE DE DIREITO DA UERJ- RFD, N. 27, 2015

especialmente no que diz respeito ao significado da exigência constitucional de que seja a compensação financeira devida ao particular justa. Como será sustentado, o simples pagamento do valor de mercado do bem suprimido não será, muitas vezes, suficiente para recompor todos os danos e prejuízos efetivamente suportados pelo expropriado.

Tal avaliação demandará, porém, a análise preliminar de alguns parâmetros constitucionais de ponderação que poderão melhor orientar o administrador, em cada caso concreto, no encontro de uma solução capaz de otimizar e conciliar os interesses que se opõem, e, consequentemente, conferir maior legitimidade à decisão estatal. E, com base em tais parâmetros balizadores, verificaremos quais valores devem, em regra, integrar a composição financeira da indenização expropriatória, de forma que reste observado o requisito constitucional e inafastável de justiça. É o que passamos a desenvolver.

\section{A constitucionalização do Direito Administrativo e a consequente e inevitável emergência de um novo regime jurídico expropriatório}

O tema do uso do poder expropriatório está, até os dias de hoje, no centro do debate acerca dos limites do controle estatal sobre a propriedade privada. Considerando-se, porém, a tutela que a atual ordem jurídica confere, expressamente, ao direito de propriedade, qualquer investigação acerca da interferência expropriatória demandará que sejam apurados, em primeiro lugar, os limites e parâmetros extraíveis da Constituição, capazes de ainda legitimar sacrifício tão extremo à esfera particular. Com isso, vai-se além da justificação baseada meramente em princípios apriorísticos a absolutos de prevalência de determinados interesses.

E essa análise se impõe, importante destacar, sobretudo em razão da obsolescência da principal norma de regência da matéria, isto é, do Decreto-lei n. 3.365, de 21 de junho de 1941, editado na vigência da Carta Constitucional de 1937, que deu início a uma era de poder conservador e autoritário, instaurando-se um Governo forte e centralizador, cuja corrente ideológica assumiu, segundo o relato do historiador BORIS FAUSTO, "a perspectiva do que se denomina modernização conservadora, ou seja, o ponto de vista de que, em um país desarticulado como o Brasil, cabia ao Estado organizar a nação para promover dentro da ordem o desenvolvimento

Versão em português recebida em 11/06/2014, aceita em 24/11/2014, e autorizada para publicação em 29/06/2015 


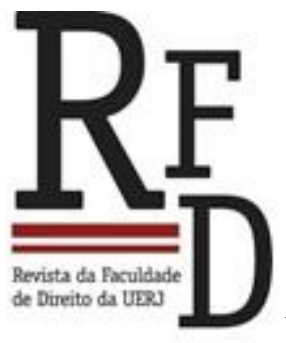

econômico e o bem-estar geral". ${ }^{2}$

REVISTA DA FACULDADE DE DIREITO DA UERJ- RFD, N. 27, 2015

A legitimidade do autoritarismo estatal fundava-se, assim, na ideia organicista de que o indivíduo era, essencialmente, uma parte do todo social, realizando-se o bem de cada um apenas na medida em que assegurado o bem comum, cuja superioridade intrínseca sobre as liberdades individuais caberia ao Estado assegurar ${ }^{3}$

Já no que diz respeito especificamente ao tratamento conferido à desapropriação, a nova ordem constitucional então instaurada pouco inovou, com a importante ressalva de que restou suprimida a exigência de ser justa a indenização, remetendo à legislação ordinária a função de regular os limites e o conteúdo do exercício do direito de propriedade.

Para tanto, foi editado, nesse contexto "não-democrático", o famigerado Decreto-lei n. 3.365/41, vigente e amplamente aplicado até os dias de hoje, não obstante a indiscutível disparidade entre o sistema sócio-político existente no país à época, início da década de 40 do século passado, e o inaugurado com a edição da Constituição de 1988, o que nos leva à seguinte perplexidade: por que razão um regime legal instituído em contexto histórico tão afastado da noção garantística que hoje prevalece segue sendo aplicado, tanto administrativa como judicialmente, com status de estatuto básico da atividade expropriatória?

Não obstante, enquanto for esse o entendimento prevalecente e enquanto não sobrevier um novo marco legal, a solução que, no momento, resta ao intéprete é a rejeição de uma mera leitura acrítica do texto legal, adotando, ao contrário, os valores e as normas constitucionais como filtro e parâmetro hermenêutico. Afinal, a edição da Carta de 1988 foi acompanhada por sua passagem para o centro da ordem jurídica, introduzindo, no país, uma nova ordem objetiva de valores, em cujo centro axiológico encontram-se os direitos fundamentais, voltados, precipuamente, para a tutela da dignidade humana. ${ }^{4}$

\footnotetext{
${ }^{2}$ FAUSTO, Boris. História do Brasil. São Paulo: Editora da Universidade de São Paulo, 1995. p. 37.

${ }^{3}$ BINENBOJM, Gustavo. Uma Teoria do Direito Administrativo: Direitos Fundamentais, Democracia e Constitucionalização. Rio de Janeiro: Renovar, 2008. p. 82.

${ }^{4}$ Como destaca Gustavo Binenbojm, "há um certo consenso na atualidade sobre o papel central das noções de direitos fundamentais e democracia como fundamentos de legitimidade e elementos constitutivos do Estado democrático de direito, que irradiam sua influência por todas as suas instituições políticas e jurídicas". BINENBOJM, Gustavo. A Constitucionalização do Direito Administrativo no Brasil: Um inventário de Avanços e Retrocessos. Revista Eletrônica sobre a Reforma do Estado (RERE), Salvador, n. 13, p. 23, mar./abr./mai. 2008. Disponível em: <http://www.direitodoestado.com/revista/RERE-13-MAR\%C7O-2007-GUSTAVOBINENBOJM. PDF>. Acesso em: 04 jun. 2013.
}

Versão em português recebida em 11/06/2014, aceita em 24/11/2014, e autorizada para publicação em 29/06/2015 


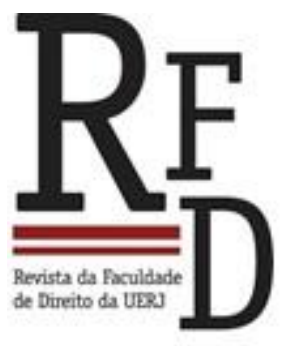

REVISTA DA FACULDADE DE DIREITO DA UERJ- RFD, N. 27, 2015

Com isso, exige-se, do intérprete, o esforço de também compatibilizar a legislação anterior a 1988 com esses novos paradigmas, ainda que, à primeira vista, possam parecer conflitantes. De fato, sendo possível ao intérprete extrair da norma mais de um sentido, a única interpretação válida e possível será aquela compatível com o texto constitucional.

Dentro desse contexto, o âmbito específico da atividade estatal expropriatória tampouco fugirá ao influxo dos ditames e diretrizes da Constituição, o que demandará a leitura de seus mais variados institutos e conceitos à luz de novos paradigmas, indo de encontro à ainda remanescente prática jurídica por meio da qual o "conteúdo e as interpretações do direito administrativo permanecem vinculados e referidos a uma realidade sociopolítica que há muito deixou de existir". 5

Nesse contexto, assim, de desconstrução ${ }^{6}$ de antigas noções, mister é que a desapropriação seja repensada para além de sua concepção tradicional como forma de aquisição originária da propriedade privada pelo Estado, através do uso de seu poder de império, em nome da suposta existência de um interesse público que sempre prevalecerá sobre os meros interesses particulares.

Ora, se, por um lado, a Carta Fundamental resguarda uma série de interesses do agrupamento social, em nome, por exemplo, do desenvolvimento da ordem econômica, da política urbana e agrária e do meio ambiente, o que acaba por resultar, em alguma medida, na inevitável compressão de direitos individuais, por outro, não se pode ignorar o amplo rol de direitos e garantias fundamentais amplamente assegurado, resultando no necessário equacionamento da dimensão coletiva com a individual.

Daí decorre que a desapropriação, consistindo em uma interferência drástica e extrema sobre a propriedade individual - de forma que acaba sempre correndo os graves riscos do autoritarismo e do abuso estatal -, deverá igualmente buscar na vontade constitucional, em cada caso, seu fundamento e seus critérios de legitimidade, de forma que sejam realizados ao máximo os distintos bens jurídicos em jogo. Para tanto, porém, muitas vezes ter-se-á de lançar

\footnotetext{
${ }^{5}$ JUSTEN FILHO, Marçal. Curso de Direito Administrativo. São Paulo: Saraiva, 2005. p. 13.

${ }^{6}$ BINENBOJM, Gustavo. A Constitucionalização do Direito Administrativo no Brasil. Op. cit. p. 8. Versão em português recebida em 11/06/2014, aceita em 24/11/2014, e autorizada para publicação em 29/06/2015
} 


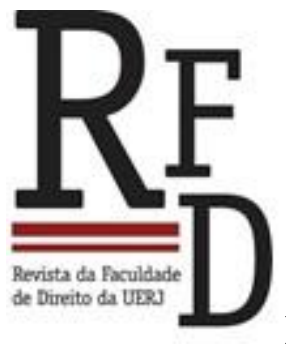

REVISTA DA FACULDADE DE DIREITO DA UERJ- RFD, N. 27, 2015

mão do uso de mecanismos racionais de correção ou adequação do texto legal sem, necessariamente, anulá-lo de forma ampla.

Ou seja, atentando-nos para a obsolescência do regime jurídico expropriatório ainda vigente, não é suficiente que, na solução dos variados conflitos envolvendo a supressão estatal da propriedade privada, o operador jurídico desenvolva um raciocínio jurídico de mera subsunção do fato à norma infraconstitucional. Isto é, que se limite à adoção dos elementos clássicos da hermenêutica tradicional, sem passar o texto da norma pelo filtro "constante e permanente da Constituição" 7 .

Importante destacar, nesse sentido, o caráter dúplice do instituto: ao mesmo tempo em que pressupõe o poder da Administração em sacrificar um direito patrimonial, sem chance de se lhe opor resistência, também consiste em um importante sistema de garantias individuais mínimas em face do Estado, necessárias para contrabalançar a potestade estatal e lhe retirar qualquer nota de arbitrariedade. $^{8}$

Daí resulta que apenas o uso argumentativo da técnica da ponderação, através da qual é possível alcançar uma solução otimizadora e conciliadora entre os interesses que se opõem em cada caso, será capaz de legitimar a decisão expropriatória, permitindo que sejam adotadas soluções intermediárias, pelas quais tanto os interesses do proprietário individual como os do ente público podem ser preservados em alguma medida.

No entanto, torna-se relevante, para fins de sistematização da interpretação do regime jurídico aplicável à matéria, que a atividade ponderativa observe alguns parâmetros e limites que podemos fixar em abstrato, apesar de sujeitos à validação no caso concreto, evitando-se, assim, a ampliação excessiva do espaço de atuação do intérprete. Com isso não se pretende, esclareça-se, enrijecer o papel do aplicador da norma, mas, ao contrário, conferir-lhe critérios mais racionais e seguros que atuarão em prol de uma atividade expropriatória mais justa,

\footnotetext{
${ }^{7}$ BALDEZ, Paulo de Oliveira Lanzellotti. A imprescindibilidade do uso da Constituição na efetiva e justa solução dos litígios. In: ANDRADE, André Gustavo Corrêa de. (org.). Constitucionalização do Direito: a Constituição como lócus da hermenêutica jurídica. Rio de Janeiro: Lumen Juris, 2003. p. 254.

8 Justamente ao tratar dessa natureza dúplice da desapropriação, o professor espanhol De la Cruz Ferrer a qualifica como "uma instituição que como nenhuma outra reflete a pecualiaridade desse ramo do Direito, situada no equilíbrio entre as prerrogativas da Administração e as garantias dos cidadãos, ocasionando as consequentes modulações jurídicas das instituições”. FERRER, de la Cruz J. Una aproximación al control de proporcionalidad del Consejo de Estado francés: el balance costes-benefícios en las declaraciones de utilidad pública de la Versão em português recebida em 11/06/2014, aceita em 24/11/2014, e autorizada para publicação em 29/06/2015
} 


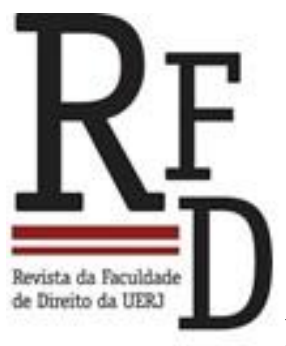

isonômica, eficiente e controlável. ${ }^{9}$

REVISTA DA FACULDADE DE DIREITO DA UERJ- RFD, N. 27, 2015

E, no âmbito específico da questão indenizatória, tema no qual nos centraremos neste estudo, podemos extrair dos princípios constitucionais da isonomia e da eficiência parâmetros passíveis de nortear o aplicador da norma em direção a uma decisão mais justa e racional, conforme passamos a analisar em sequência.

\section{0 princípio da isonomia e a justa repartição dos encargos e benefícios sociais}

De forma geral, diz-que que o princípio da isonomia ou da equidade, estabelecido no caput do art. $5^{\circ}$ da Constituição, significa tratar igualmente os iguais e desigualmente os desiguais. Mas a sua importância para o presente tema decorre, principalmente, da sua aproximação com a interpretação conforme a Constituição. Isso porque, como já dito, através desse instrumental hermenêutico, o intérprete procura afastar as possibilidades de intepretação da norma incompatíveis com a Carta Política, respeitados os limites do seu texto. E o princípio da isonomia encaixa-se nesse contexto na medida em que sua adoção pelo intérprete o conduz a uma interpretação conforme a justiça do caso concreto, isto é, a uma interpretação conforme a equidade da regra, tendo em conta os princípios constitucionais que, direta ou indiretamente, fundamentam a exigência de justiça. ${ }^{10}$

E para que seja conferida ao regime jurídico expropriatório, destacadamente no que se se refere às regras indenizatórias, uma interpretação em conformidade com o texto constitucional focaremos, aqui, em uma das diversas manifestações da isonomia, qual seja, a exigência de que, na sociedade, haja uma equitativa distribuição dos encargos e benefícios entre todos - ou quase todos - os seus membros, de forma que o ônus de determinada utilidade pública fruível pela coletividade em geral não recaia injustamente apenas sobre determinados e poucos sujeitos.

De forma diversa não poderia se dar em um Estado democrático de Direito, que

expropiación forzosa. Revista Española de Derecho Administrativo, Madrid, n. 45, p. 71, 1985.

9 BARCELLOS, Ana Paula de. Alguns parâmetros normativos para a ponderação constitucional. In: BARROSO, Luís Roberto (org.). A nova interpretação constitucional: ponderação, direitos fundamentais e relações privadas. 2. ed. Rio de Janeiro: Renovar, 2006. p. 59.

${ }^{10}$ BARCELLOS, Ana Paula. A eficácia jurídica dos princípios constitucionais: o princípio da dignidade da pessoa humana. Rio de Janeiro: Renovar, 2002. p. 102-103.

Versão em português recebida em 11/06/2014, aceita em 24/11/2014, e autorizada

para publicação em 29/06/2015 


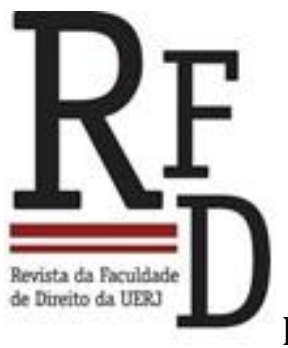

REVISTA DA FACULDADE DE DIREITO DA UERJ- RFD, N. 27, 2015

pressupõe o equilíbrio social e, portanto, a impossibilidade de imposição de sacrifícios individuais especiais e exorbitantes, compensados por um ganho "superior" dos interesses dos demais integrantes da comunidade, concepção esta indiscutivelmente autoritária. E isso implica que a equidade seja buscada também, e principalmente, no momento de fixação da indenização que cabe ao particular expropriado. De fato, a compensação financeira a que tem direito o proprietário para recompor a perda material sofrida consiste no principal mecanismo constitucional de repartição, pela comunidade beneficiada, do ônus decorrente da ação pública expropriatória.

Um exemplo pode esclarecer o ponto. Pensemos nas desapropriações voltadas para fins ambientais, como no caso de criação de áreas de proteção permanente (APP), em propriedade privada, objetivando-se a proteção de determinados recursos naturais ${ }^{11}$. Considerando-se que o art. 225 da Constituição de 1988 define o meio ambiente ecologicamente equilibrado como um bem de uso comum do povo, constituindo, portanto, um direito-dever titularizado por toda a sociedade, sua defesa e preservação incumbem não apenas ao Poder Público, mas igualmente à coletividade como um todo, de maneira que também o custo social daí decorrente deve ser compartilhado.

Consequentemente, a carga que incide sobre o particular que sofre, de fato, a perda da propriedade pelo completo esvaziamento de seu conteúdo econômico, para fins de proteção e equilíbrio do meio ambiente, deve ser equitativamente repassada à coletividade beneficiada por via do pagamento de indenização prévia e justa ao particular especialmente atingido.

Nesse tocante, ANA PAULA DE BARCELLOS mostra-nos que:

(...) o caso concreto frequentemente apresentará particularidades que não foram previstas de forma geral pelo legislador. Assim, ao aplicar a norma, o juiz poderá introduzir um elemento adicional: a equidade, que autoriza adaptar a norma e suas consequências de acordo com as características próprias do caso. Trata-se, como se tornou corrente referir, da justiça do juiz ou da justiça do caso concreto, (...). ${ }^{12}$

O mesmo raciocínio poderíamos também estender, por exemplo, às desapropriações

\footnotetext{
${ }^{11}$ Conforme estabelece o art. $3^{\circ}$, da Lei n. 12.651/2012 (que dispõe sobre a proteção da vegetação nativa), “Área de Preservação Permanente - APP" é a área protegida, coberta ou não por vegetação nativa, com a função ambiental de preservar os recursos hídricos, a paisagem, a estabilidade geológica e a biodiversidade, facilitar o fluxo gênico de fauna e flora, proteger o solo e assegurar o bem-estar das populações humanas.
}

12 BARCELLOS, Ana Paula de. Op. cit. p. 100-102.

Versão em português recebida em 11/06/2014, aceita em 24/11/2014, e autorizada para publicação em 29/06/2015 


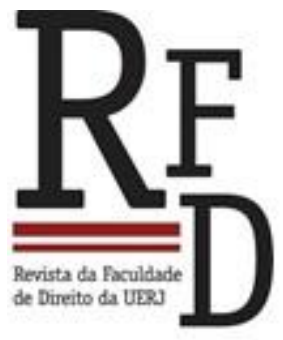

REVISTA DA FACULDADE DE DIREITO DA UERJ- RFD, N. 27, 2015

realizadas para fins de promoção e proteção do patrimônio cultural brasileiro, também usufruível por todos os membros de uma determinada comunidade, nos termos do $\S 1^{\mathrm{o}}$ do art. 226 da Constituição. Ao tratar desse contexto específico, CELSO ANTONIO BANDEIRA DE MELLO defende, nessa linha, que a "entender-se de outro modo, alguns seriam forçados a suportar desproporcionalmente ônus estabelecidos em nome do interesse de todos, no que estaria ferindo o princípio constitucional da isonomia". ${ }^{13}$

É o que expõe, ainda, na Espanha, GARCÍA DE ENTERRÍA, quando afirma que a desapropriação não altera o status geral da propriedade, por não acarretar a perda do conteúdo econômico da situação sacrificada, conteúdo que é tão somente substituído pelo seu equivalente pecuniário, de forma que "a carga pública que a extinção da propriedade supõe não recaia sobre a pessoa do afetado, mas seja repartida entre toda a coletividade, através do sistema fiscal que nutre os fundos de que a indenização procede". ${ }^{14}$

Portanto, a integral compensação financeira do particular expropriado, mediante a recomposição de todos os danos e prejuízos por ele suportados, representa nada mais do que decorrência lógica e obrigatória da equidade, a demandar uma cuidadosa análise caso a caso. Com isso cai por terra a adoção de fórmulas genéricas e simplificadas, que impossibilitam a consideração das peculiaridades concretas e, em consequência, que o particular retorne, na maior medida possível, ao seu status quo ante.

\section{A eficiência da supressão forçada da propriedade com base em uma análise econômica do instituto expropriatório}

Para a teoria econômica clássica, as trocas econômicas - sejam voluntárias ou não têm, como objetivo principal, a transferência eficiente de recursos, que, sob condições ideais, pode (e deve) ser alcançada através das trocas comuns de mercado. Hipótese, portanto, em que o papel estatal estará limitado à proteção dos direitos de propriedade e à imposição do cumprimento das obrigações pactuadas entre os agentes privados. Consequentemente,

\footnotetext{
${ }^{13}$ MELLO, Celso Antonio Bandeira de. Curso de Direito Administrativo. 21. ed. São Paulo: Malheiros, 2006. p. 766.

${ }^{14}$ ENTERRÍA, Eduardo García de; FERNÁNDEZ, Tomás-Ramón. Curso de Derecho Administrativo. vol. II. Madrid: Editorial Civitas, 1999. p. 220.

Versão em português recebida em 11/06/2014, aceita em 24/11/2014, e autorizada para publicação em 29/06/2015
} 


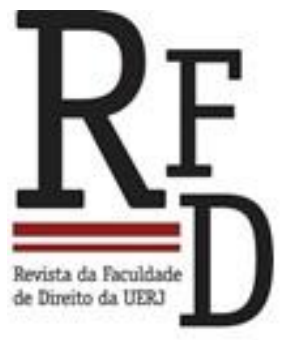

REVISTA DA FACULDADE DE DIREITO DA UERJ- RFD, N. 27, 2015

qualquer forma de intervenção pública além destes limites deve ser justificada, sob um ponto de vista econômico, em face da incapacidade de o mercado operar eficientemente por conta própria, fenômeno conhecido como falhas de mercado.

E, no caso específico da intervenção estatal via desapropriação, uma das justificativas econômicas capaz de legitimá-la parte do pressuposto de que a sua adoção pelo Estado atingirá o ponto ótimo de eficiência quando restar configurada, em cada caso, a oposição de grave e intransponível resistência por parte dos titulares dos bens pretendidos, podendo dificultar ou mesmo inviabilizar o projeto público ambicionado. É o que se denomina, no direito norte-americano, de holdout problem, ou, traduzindo para o português, "problema de resistência".

Diante, assim, de tais circunstâncias e, revelando-se economicamente mais valiosa a utilização conjunta dos bens particulares para uma única finalidade em comparação com o uso individualmente considerado ${ }^{15}$, necessário se torna a adoção de instrumento jurídico de coerção capaz de superar o poder de monopólio ou barganha dos proprietários privados. Como resultado, será menos dispendiosa e mais célere - e, portanto, mais eficiente - a obtenção do resultado público que se pretende.

Por outro lado, uma vez revelando-se imprescindível a desapropriação, torna-se fundamental a coordenação, na maior medida possível, de todos os interesses envolvidos para que se alcance o ponto ótimo de eficiência no processo de obtenção forçada da propriedade privada, notadamente mediante a oferta, ainda na fase administrativa, dita "amigável", de valor indenizatório que seja, sob a perspectiva subjetiva, verdadeiramente justo. Isso porque, quando a Administração oferta, neste primeiro momento, montante consideravelmente aquém do valor capaz de satisfazer integralmente o particular afetado, incrementa-se a probabilidade de que sua recusa protele a solução do impasse para o, em geral, demorado e custoso processo judicial.

E, com isso, compromete-se a eficiência econômica da medida expropriatória como um todo, haja vista que é postergada, para um segundo momento, a transferência da propriedade privada pretendida e, consequentemente, a realização do projeto público

\footnotetext{
${ }^{15}$ MICELI, Thomas J. The economic theory of eminent domain: private property, public use. Cambridge: Versão em português recebida em 11/06/2014, aceita em 24/11/2014, e autorizada para publicação em 29/06/2015
} 


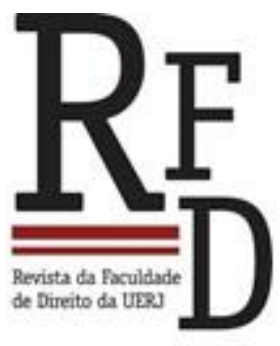

REVISTA DA FACULDADE DE DIREITO DA UERJ- RFD, N. 27, 2015

planejado. Ou seja, a judicialização da desapropriação envolve um alto custo de oportunidade para o Estado, que poderia ser mitigado com a antecipada resolução amigável da questão indenizatória, pagando-se ao proprietário, na maior medida possível, o valor que, em concreto, é o mais justo.

Não bastasse, ao lado da ineficiência ocasionada pelos custos da demora, essa postergação sujeitará a Administração, ainda, a elevados custos financeiros, notadamente os decorrentes do pagamento de juros compensatórios destinados a compensar a perda antecipada da propriedade (em razão de eventual e provável imissão provisória na posse) até a sua transferência efetiva via sentença judicial definitiva.

Portanto, ao contrário do que se pode pensar em um primeiro momento, o envido de esforços para que o particular seja indenizado, de antemão, de todos os danos por ele sofridos em razão da perda da propriedade, inclusive os de natureza subjetiva, será financeiramente mais vantajoso para o Estado, além de antecipar a satisfação da finalidade pública em jogo.

Importante ressaltar, porém, antes de prosseguirmos, que, apesar da utilidade deste parâmetro, principalmente em termos de racionalidade, não se pretende afirmar que a teoria econômica e seus critérios de eficiência possam oferecer uma resposta completa de como a atividade expropriatória deve se desenvolver. Até porque o Direito, enquanto uma instituição social, deve servir a propósitos que vão além da eficiência, tais como a promoção da equidade e da justiça social, das quais o estudo econômico não dá conta por si só. E, por outro lado, tampouco conseguiria a teoria econômica captar todas as dimensões políticas que envolvem a decisão estatal de desapropriar. Por isso, importante se mostra a adoção de variadas perspectivas no estabelecimento de parâmetros e limites balizadores da atividade expropriatória, voltadas para a consecução de outros valores constitucionais de igual relevo.

\section{0 significado constitucional da justa indenização expropriatória ${ }^{16}$}

Cambridge University Press, 2011. p. 163.

16 Em razão da limitação de espaço e tendo em vista que o foco deste estudo é, principalmente, a constitucionalidade do regime jurídico decorrente da aplicação do Decreto-lei n. 3.365/41, não abordaremos, aqui, as hipóteses de desapropriação-sanção, para as quais a Constituição estabelece, no caso da desapropriação para fins de reforma agrária, o pagamento de indenização através de títulos da dívida agrária, resgatáveis no prazo de até vinte anos, a partir do segundo ano de sua emissão (art. 184, CF); e, no caso da desapropriação para fins urbanísticos, o pagamento através de títulos da dívida pública, com prazo de resgate de até dez anos, em Versão em português recebida em 11/06/2014, aceita em 24/11/2014, e autorizada para publicação em 29/06/2015 


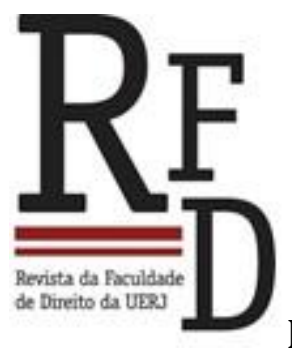

REVISTA DA FACULDADE DE DIREITO DA UERJ- RFD, N. 27, 2015

Indiscutível é que a chamada justa e prévia indenização representa um dos principais elementos do sistema de garantias individuais em face do poder estatal expropriatório. Mas, diante da sua abertura semântica, o que se deve entender como sendo uma indenização justa? Isto é, considerados os parâmetros da equidade e da eficiência, quais valores devem integrar a sua composição para que o particular seja integralmente recompensado por todas as perdas e danos individualmente suportados em benefício da coletividade?

Há, na verdade, uma grande aceitação, sobretudo em decorrência de construção jurisprudencial, em torno da ideia que associa "justa indenização" a "valor de mercado" do bem. No entanto, não obstante o amplo consenso nesse sentido, parece-nos que a expressão, que constitui garantia constitucional expressa, merece maiores reflexões, tendo em vista que o decreto-lei, em seu art. 27, estabelece, de forma ampla e genérica, que, na fixação do quantum indenizatório, o convencimento judiciário deverá se dar com base na "estimação dos bens para efeitos fiscais; ao preço de aquisição e interesse que deles aufere o proprietário; à sua situação, estado de conservação e segurança; ao valor venal dos da mesma espécie, nos últimos cinco anos, e à valorização ou depreciação de área remanescente, pertencente ao réu". O dispositivo confere, assim, um amplo espaço de interpretação para o aplicador da norma.

Imprescindível, portanto, que o administrador e, quando for o caso, o juiz, orientem-se com base em critérios objetivos e racionais, considerando-se que, embora devam ser observados, em princípio, os elementos mencionados na norma, não está obrigado o intérprete a eles se limitar. Ao contrário, outros fatores podem - e devem - ser sopesados na fixação do compensação financeira devida e, dependendo das circunstâncias concretas, poderá revelar-se necessário até mesmo desprezar os critérios legais, levando-se em conta outros mais pertinentes ao caso. ${ }^{17}$

Nessa linha, CELSO ANTONIO DE MELLO considera que a indenização justa deve, além de habilitar o proprietário a adquirir outro bem perfeitamente equivalente, eximi-lo de

parcelas iguais e sucessivas (art. 182, $\S 4^{\circ}, \mathrm{CF}$ ).

${ }^{17}$ É o que expõe com clareza Washington de Barros Monteiro, quando afirma que "Na decisão, basear-se-á a autoridade judiciária nos critérios preconizados pelo art. 27, do Dec.-lei 3.365, que, todavia, não são inflexíveis e rígidos, podendo, por isso, ser abandonados, já que a indenização tem de ser justa, real, compreensiva dos legítimos interesses do expropriado". MONTEIRO, Washington de Barros. Curso de Direito Civil: Direito das Coisas. São Paulo: Saraiva, 1975. p. 179.

Versão em português recebida em 11/06/2014, aceita em 24/11/2014, e autorizada para publicação em 29/06/2015 


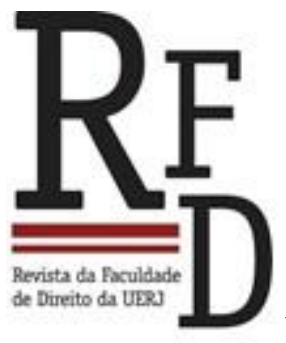

REVISTA DA FACULDADE DE DIREITO DA UERJ- RFD, N. 27, 2015

qualquer detrimento, permanecendo seu patrimônio "sem desfalque algum". ${ }^{18}$ Isso implicará, consequentemente, que, além de componentes de natureza objetiva, outros elementos, que aqui denominaremos de "subjetivos", poderão ter de integrar o montante indenizatório, de forma que, conforme assim o exijam as circunstâncias em concreto, sejam apuradas parcelas adicionais. Passemos, assim, a esclarecer melhor o ponto.

\subsection{O componente subjetivo da indenização}

Antes de iniciarmos a análise do dito "componente subjetivo", vale destacarmos as premissas nas quais a análise que segue irá se basear: em primeiro lugar, nem sempre a quantia correspondente ao simples valor de mercado, incluindo os componentes objetivos da indenização, será capaz de atribuir ao desapropriado o valor lhe foi efetivamente subtraído, sem que se lhe cause um empobrecimento indevido ou uma lesão excessiva e intolerável. Por outro lado, não há dúvidas de que o ideal de justiça nunca será plenamente alcançado, já que quaisquer métodos de avaliação que sejam utilizados sempre se ressentirão das falhas humanas. No entanto, isso não justifica que não se tente buscar o ideal com a máxima intensidade, recompondo-se o desfalque sofrido pelo particular na maior medida possível, ao invés da simples adoção de métodos de valoração justificados tão somente em razão de sua simplicidade, praticidade e segurança.

Essa nova percepção quanto à justiça da indenização implicaria, portanto, a superação do entendimento prevalecente no âmbito da Administração no sentido de que a "indenização do imóvel ter por base [tão somente] o valor de mercado assegura a inocorrência de prejuízo, considerando que, para fins de venda, terminaria mesmo sendo valorado ante o mercado imobiliário local". ${ }^{19}$

Assim, ao lado do que podemos denominar de componentes objetivos da compensação, a exemplo do valor do próprio bem e demais parcelas acessórias, tais como juros moratórios, compensatórios, honorários advocatícios e correção monetária, é

\footnotetext{
${ }^{18}$ MELLO, Celso Antônio Bandeira de. Op. cit. p. 840-842.

${ }^{19}$ Tribunal de Contas da União - TCU. Primeira Câmara. Acórdão 1.190/2008. Min. rel. Guilherme Palmeira. abr. 2008.

Versão em português recebida em 11/06/2014, aceita em 24/11/2014, e autorizada para publicação em 29/06/2015
} 


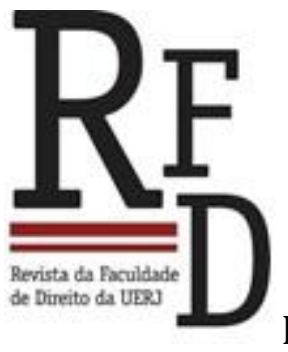

REVISTA DA FACULDADE DE DIREITO DA UERJ- RFD, N. 27, 2015

plenamente sustentável a ideia de que cabe ao aplicador jurídico verificar, à luz do caso concreto, todas as demais lesões efetivamente suportadas pelo particular.

Há dificuldade, porém, de que a justa compensação, dentro dessa perspectiva, equivalha à integral compensação em um sentido econômico, haja vista que o componente subjetivo é de difícil aferição financeira pelo intérprete e pode ser mal ou excessivamente representado pelo proprietário em seu próprio benefício. ${ }^{20}$

Adotando um posicionamento contrário à inclusão desses elementos no montante indenizatório, o norte-americano THOMAS J. MICELI sustenta, com base em argumentos econômicos, que: (i) no contexto de projetos privados de desenvolvimento, nos quais se utiliza o poder expropriatório em favor de terceiro particular, são produzidos, normalmente, efeitos externos que beneficiam o público em geral, mas não são capturáveis pelo investidor privado, de forma que pagar menos que a integral compensação poderia ser uma forma de subsidiar esse tipo de empreendimento; e (ii) haveria o "perigo moral" (moral hazard) de o particular ser incentivado a investir excessivamente e de má-fé na propriedade sujeita a uma provável e iminente transferência forçada, para fins de obtenção da vantajosa compensação integral. ${ }^{21}$ Como resultado, tal sobreinvestimento no bem acabaria por ser arcado às custas do ente expropriante e, portanto, da coletividade.

Em contraposição a esse entendimento, porém, podemos extrair, do Direito comparado, diferentes modelos jurídicos bem-sucedidos que buscam conferir, das formas mais variadas, algum grau de proteção ao componente subjetivo do direito de propriedade. Modelos estes que, de alguma forma, podem inspirar sua implementação também no ordenamento jurídico pátrio.

Na Colômbia, por exemplo, que possui um sistema avançado e inovador de ordenação da ocupação do solo, a indenização pode ter natureza compensatória, reparatória ou restitutiva, de acordo com as especificidades de cada caso $^{22}$, que determinarão a ponderação proporcional e em concreto dos interesses envolvidos ${ }^{23}$. Daí decorre que, conforme

\footnotetext{
${ }^{20}$ MICELI, Thomas J. Op. cit. p. 154.

${ }^{21}$ Para aprofundamento desse e de outros argumentos no mesmo sentido, cf. Ibid. p. 154-155.

22 FERNANDES, Edésio; ALFONSIN, Betânia. Op. cit. p. 29.

${ }^{23}$ PINILLA PINEDA, Juan Felipe; VILLEGAS DEL CASTILLO, Catalina. Las alternativas del derecho Versão em português recebida em 11/06/2014, aceita em 24/11/2014, e autorizada para publicação em 29/06/2015
} 


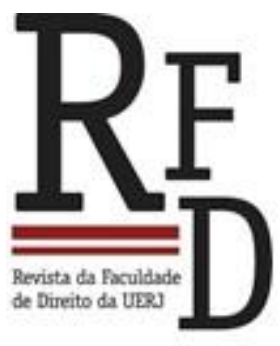

REVISTA DA FACULDADE DE DIREITO DA UERJ- RFD, N. 27, 2015 esclarecem JUAN FELIPE PINEDA e CATALINA DEL CASTILLO à luz do Direito colombiano:

(...) ao serem consultados os interesses do afetado e adquirindo estes uma relevância constitucional especial, como no caso da moradia familiar e de outros direitos analisados na sentença judicial, a indenização pode, tanto em seu montante quanto na sua forma de pagamento, assumir uma modalidade que a leve a cumprir uma função restitutiva. ${ }^{24}$

Ou seja, o cálculo da indenização, lá, não seguirá uma fórmula genérica, demandando do intérprete a avaliação concreta das necessidades específicas do particular afetado e da comunidade beneficiada. Ora as circunstâncias exigirão uma tutela mais intensa dos interesses pessoais do particular, inclusive extrapatrimoniais, ora resultarão apenas na proteção dos seus interesses financeiros. A opção por uma ou outra alternativa dependerá, assim, da natureza dos valores subjacentes ao exercício do direito de propriedade, podendo variar de valores meramente econômico-financeiros até valores existenciais.

Já no Direito norte-americano, conforme descreve a professora NICOLE GARNETT, algumas soluções têm sido formuladas para se minimizar, na maior medida possível, o problema da subcompensação provocado pelo uso do tradicional critério baseado no fair market value, tais como: (i) evitar desapropriar bens que contenham um "elevado valor subjetivo" (high subjective value properties), como, por exemplo, aqueles utilizados como moradia do particular ou como local de sua subsistência; (ii) conferir ao expropriado compensação adicional na forma de uma "assistência para realocação" (relocation assistance); (iii) indenizar, ainda na fase amigável da desapropriação, valor acima do de mercado (above-market compensation), para se evitar o desgaste próprio do uso da via judicial $^{25}$; e, (iv) por fim, recompor as perdas não patrimoniais sofridas (uncompensated increments), incluindo os danos à sua dignidade. ${ }^{26}$

O que se pode concluir, portanto, da análise desses dois modelos, independentemente

urbano colombiano para la obtención pública de suelo: entre las formas expropriatórias tradicionales y las nuevas formas de gestión del suelo. In: FERNANDES, Edésio; ALFONSIN, Betânia (coord.). Revisitando o instituto da desapropriação. Belo Horizonte: Fórum, 2009. p. 151.

${ }^{24}$ Loc. cit.

25 GARNETT. Nicole Stelle. The neglected political economy of eminent domain. Disponível em: <http://papers.ssrn.com/sol3/papers.cfm?abstract_id=875412>. Acesso em: 30 jan. 2012.

Versão em português recebida em 11/06/2014, aceita em 24/11/2014, e autorizada para publicação em 29/06/2015 


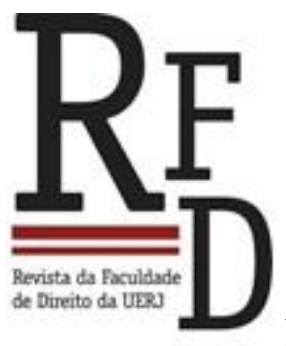

REVISTA DA FACULDADE DE DIREITO DA UERJ- RFD, N. 27, 2015

da discussão em torno da sua total aplicabilidade ou não ao contexto jurídico pátrio, é que a recomposição dos prejuízos decorrentes da supressão do direito dominial imposta pelo Estado pode ir, como dito, muito além do mero valor de mercado do bem ${ }^{27}$.

E justamente com essa finalidade, a Constituição do Estado norte-americano de Michigan, por exemplo, já estabelece expressamente que, quando a propriedade subtraída consistir na principal moradia do expropriado, o valor indenizatório deverá ser equivalente a, no mínimo, $125 \%$ do valor de mercado do imóvel, em acréscimo aos demais danos sofridos:

\section{$\S 2$ Desapropriação; compensação.}

Sec. 2. A propriedade privada não deve ser suprimida para uso público sem a justa compensação, assegurada da forma prescrita em lei. Se a propriedade privada consistente na principal residência do indivíduo for suprimida para uso público, o montante da compensação a ser fixado não deve ser inferior a $125 \%$ do valor de mercado do bem, somado a outras parcelas determinadas por lei. ${ }^{28}$

Ou seja, a própria norma confere, de antemão, tratamento diferenciado de acordo com a natureza do dano sofrido, considerando mais grave à esfera individual a hipótese em que a desapropriação atinge não apenas interesses patrimoniais do particular, mas, principalmente, seu direito de moradia. Torna, assim, mais objetiva a aferição do dano de cunho subjetivo, conferindo mais segurança e isonomia à atuação do intérprete.

Já no contexto pátrio, por outro lado, é praticamente consenso, tanto doutrinário como jurisprudencial, que o denominado valor de afeição do bem não deve ser levado em conta no momento em que é fixada a indenização expropriatória, por, supostamente, haver real impossibilidade de traduzi-lo economicamente, dizendo respeito tão somente ao foro íntimo do proprietário.

Nessa linha, JOSÉ CARLOS SALLES, partindo da premissa de que o "ressarcimento

\footnotetext{
${ }^{26}$ Ibid. p. 106-110.

27 Vale mencionar, inclusive, que situações pode haver em que nem mesmo existirá, de fato, um valor de mercado que sirva como critério de avaliação do bem, como, por exemplo, a desapropriação de terrenos valorizados em razão de sua própria preservação ambiental, hipótese em que não há um mercado concorrencial que permita a obtenção de um número significativo de elementos comparativos. Para uma abordagem mais detalhada a esse respeito, cf. HADDAD, Emílio; SANTOS, Cacilda Lopes dos. Desapropriação de áreas de interesse ambiental. In: FERNANDES, Edésio; ALFONSIN, Betânia (coord.). Op. cit. p. 242-243; e BALDI, César Augusto. Territorialidade étnica e proteção jurídica: as comunidades quilombolas e a desapropriação. In: Ibid. p. 304.
}

28 Texto da norma disponível em <http://www.legislature.mi.gov/(S(jgpxne55bzbyol45fnd2ulzv))/ mileg.aspx ?page $=$ GetObject\&object name $=$ mcl-Article-X-2>. Acesso em: 30 mai. 2013.

Versão em português recebida em 11/06/2014, aceita em 24/11/2014, e autorizada para publicação em 29/06/2015 


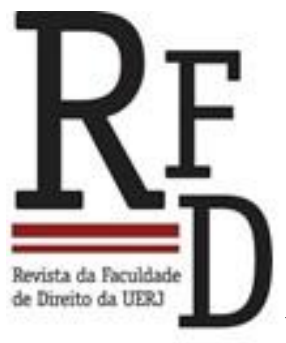

REVISTA DA FACULDADE DE DIREITO DA UERJ- RFD, N. 27, 2015

decorrente da expropriação há de ser palpável, concreto, calculado em bases reais e assentado em dados comumente considerados no mercado mobiliário e imobiliário para os bens da mesma espécie" 29 , estabelece uma distinção entre o valor de afeição ou estimativo do bem e o seu valor de interesse.

Esclarecendo, valores de interesse consistiriam no desfalque patrimonial, de natureza objetiva, sofrido pelo expropriado em razão da perda do interesse econômico-financeiro associado ao seu direito dominial, como, por exemplo, o dano material decorrente da perda do estabelecimento em que até então explorada sua atividade comercial. Já os valores afetivos corresponderiam ao valor aferido pelo vínculo subjetivo estabelecido entre o próprio titular e o bem expropriado, a partir de considerações de natureza pessoal.

Partindo, assim, desta distinção, JOSE SALLES - que é acompanhado pela grande maioria de nossa doutrina - defende que apenas os ditos valores de interesse podem e devem ser indenizados, na medida em que sua aferição econômica pode, a seu ver, advir de "fatores especialíssimos contidos na coisa, que fazem com que esta contenha, intrinsicamente, um interesse a ser auferido de modo concreto pelo dono". ${ }^{30}$

Por sua vez, valores de afeição ou puramente subjetivos poderiam compor, segundo PAULO DE ARAÚJO LIMA, apenas o quantum devido em razão de relações jurídicas estabelecidas na esfera privada, no âmbito do Direito Civil, no qual, "sendo a proteção assegurada à propriedade global, abrangendo o uso, o gozo e a integral disposição, outra é a regra". E, acrescenta o autor:

\begin{abstract}
Para restituir o equivalente, quando não exista a própria coisa, estimar-se-á ela pelo seu preço ordinário e pelo de afeição, contanto que este não se avantaje àquele. Em face do direito público, mais precisamente da desapropriação, inviolável tão somente a faculdade de substituir a coisa por outra equivalente, não há como adicionar esse elemento ao acervo indenizatório. ${ }^{31}$
\end{abstract}

Ou seja, reconhece o jurista, expressamente, que o valor que o proprietário poderia obter no âmbito de relações privadas de transferência imobiliária seria sempre superior ao

\footnotetext{
${ }^{29}$ SALLES, José Carlos de Moraes. A Desapropriação à luz da doutrina e da jurisprudência. 6 . ed. rev. atual. e ampl. São Paulo: Revista dos Tribunais, 2009. p. 453.

${ }^{30}$ Ibid. p. 453.

${ }^{31}$ LIMA, Paulo de Araújo. Imissão na posse dos bens expropriados. Revista de Direito Administrativo - RDA, Rio de Janeiro, v. 82, p. 407, out./dez. 1965.

Versão em português recebida em 11/06/2014, aceita em 24/11/2014, e autorizada para publicação em 29/06/2015
} 


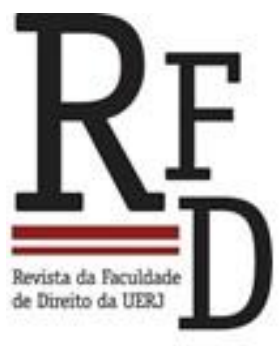

REVISTA DA FACULDADE DE DIREITO DA UERJ- RFD, N. 27, 2015

valor que the cabe em sede de desapropriação, na medida em que restariam excluídos da indenização expropriatória componentes que, em regra, integram transações voluntárias. Mas, diante dessa afirmação, fazemos a seguinte reflexão: não seria justa apenas a indenização expropriatória que correspondesse ao mesmo valor que o proprietário obteria em relações livres de mercado? Isto é, em relações em que a propriedade é transferida voluntariamente pelo particular? Caso contrário, é inegável afirmar que o expropriado acaba por sofrer um grave prejuízo financeiro em detrimento de um interesse da coletividade, havendo, com isso, uma desigual repartição dos encargos e benefícios sociais, como já tratado acima.

Semelhante compreensão resultou, já há alguns anos, em decisão proferida pelo Tribunal de Justiça de São Paulo, que, contrapondo-se ao entendimento da ampla maioria da nossa doutrina, julgou ser cabível indenizar tanto o valor de interesse ou de conveniência, como o valor afetivo do bem, nos seguintes termos:

O valor da conveniência (...) não deve ser confundido com o valor da afeição. Este
prende-se às lembranças e às considerações de ordem puramente intelectual, o valor
de conveniência é antes de ordem material. Ele se liga a certos arranjos
(aménagements), a certas comodidades, a uma combinação do imóvel mais ou
menos vantajosa para o ocupante e para ele só. Este valor tem um caráter preciso e
positivo e o expropriado deve ser especialmente indenizado por isso, porque ele tem
direito ao valor inteiro que possui a propriedade especialmente para ele e deve ele
sair da expropriação perfeitamente indene (...). ${ }^{32}$

E nos parece ser justamente esse o entendimento mais adequado à cláusula constitucional que ordena ser justa a indenização. Se voltarmos aos argumentos apresentados pelo norte-americano THOMAS J. MICELI, que repudia a inclusão de parcelas subjetivas no montante da indenização, diversos são os argumentos em sentido contrário que podemos listar.

Quanto ao primeiro, no sentido de que o não pagamento da indenização integral seria forma de subsidiar empreendimentos privados de interesse da sociedade, pergunta-se: esta suposta forma de financiamento público deve se dar unicamente às custas do particular proprietário? Não deveria a sociedade, como um todo, arcar com os custos de um projeto de

\footnotetext{
${ }^{32}$ Tribunal de Justiça do Estado de São Paulo - TJ-SP. Apelação Cível 112-932. Des. rel. Prado Fraga. RDA $75 / 211$.

Versão em português recebida em 11/06/2014, aceita em 24/11/2014, e autorizada para publicação em 29/06/2015
} 


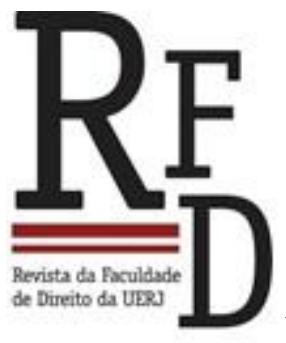

REVISTA DA FACULDADE DE DIREITO DA UERJ- RFD, N. 27, 2015

interesse coletivo, conforme orienta o já citado princípio da equitativa repartição dos encargos sociais?

Já quanto ao argumento econômico no sentido de que a compensação integral pode gerar o risco moral de um investimento desmesurado e de má-fé no bem, visando o proprietário beneficiar-se com possível futura indenização estatal, encontramos a resposta em nossa própria legislação expropriatória, que estabelece, adequadamente, que as benfeitorias de natureza voluptuária, realizadas pelo particular mesmo após declarada a utilidade pública do bem, não são indenizáveis, tendo em vista que se destinam a seu mero deleite ou recreio. Por sua vez, as benfeitorias consideradas necessárias e úteis serão indenizadas, desde que, no caso das últimas, sejam previamente aprovadas pelo ente que já tiver declarado a utilidade pública do bem. Evitam-se, com isso, riscos de locupletamento indevido do futuro expropriado.

Por fim, não se poderia aqui esquecer do contra-ponto central: é a nossa própria Constituição que estabelece, como uma das principais garantias individuais no âmbito da atividade expropriatória, a obrigatoriedade de justa indenização, o que torna difícil sustentar que a expressão justa possa significa algo menos que o equivalente à integral compensação de todos os danos e prejuízos efetivamente sofridos e à recomposição da situação original do particular. A complexa e difícil determinação de cada um dos componentes da indenização, seja de que natureza forem, não pode ser justificativa para que os mesmos sejam simplesmente deixados de lado pelo intérprete. Mesmo elementos menos tangíveis podem ser sistematicamente objetivados pelo intérprete mediante a concepção prévia e abstrata de critérios que possam refletir o valor de afeição do bem sob determinadas condições, conferindo-se tratamento equânime a particulares que se encontrem em posição semelhante.

No direito brasileiro, apesar de ser plenamente aceito o dano moral indenizável definido como a lesão que afeta a personalidade e, de alguma forma, ofende a moral e a dignidade da pessoa, desde que real, aferível e possível -, ele não necessariamente irá corresponder à totalidade do dano subjetivo sofrido pelo proprietário, que poderá se revelar, no caso concreto, ainda mais abrangente.

Para esclarecer, utilizemos, como exemplo, mais uma vez, o direito de moradia, que é, em geral, intrínseco à subsistência do indivíduo e à sua capacidade de autodesenvolvimento, não se podendo ignorar, em razão disso, que ele acaba por compor o valor afetivo que o Versão em português recebida em 11/06/2014, aceita em 24/11/2014, e autorizada para publicação em 29/06/2015 


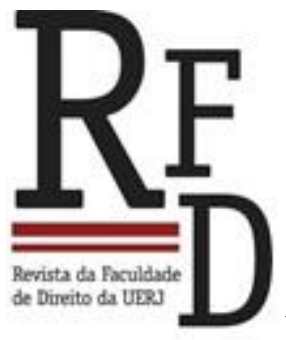

REVISTA DA FACULDADE DE DIREITO DA UERJ- RFD, N. 27, 2015

proprietário comumente atribui ao próprio bem quando nele reside. Nesse caso, portanto, não haveria muitas dúvidas quanto à importância de o intérprete considerar, além do valor de mercado do bem, uma parcela correspondente à perda subjetiva da moradia (e a sua dimensão existencial para o indivíduo).

Ocorre que, não havendo, em nossa legislação, montante objetivo predeterminado, pode o aplicador levar em conta na sua aferição, por exemplo, as reais condições e possibilidades que tem o particular para realocar sua moradia ou se a mesma constitui, também, sua fonte de subsistência. Pode avaliar, ainda, se o bem se destina especificamente à moradia de alguma comunidade, grupo ou etnia cultural, cujo desenvolvimento esteja intrinsicamente ligado à propriedade afetada.

Assim, podemos concluir, de lege ferenda, que, para determinadas hipóteses, seria recomendável, como forma de se objetivar em alguma medida o componente subjetivo da indenização, prefixar-se na própria legislação um montante adicional ao valor de mercado. $\mathrm{Ou}$, como alternativa e enquanto tal solução não sobrevier, poderia a própria prática reiterada dos órgãos administrativos e dos tribunais construir critérios precisos e seguros para sua aferição em casos semelhantes.

Mas não se há de esquecer, por fim, da importância da eficiência econômica enquanto parâmetro de ponderação no processo de aferição do montante indenizatório. Como já discutido acima, a oferta, pela Administração, em sede de negociação amigável, de valor consideravelmente aquém do que o particular potencialmente poderia obter no âmbito de relações livres de mercado, aumenta a probabilidade de se opor alguma forma de resistência (holdout), que conduzirá, inevitavelmente, às vias judiciais e, consequentemente, atrasará ainda mais a satisfação da finalidade pública pretendida. Por essa razão, ofertar de antemão montante que inclua o valor de afeição que o titular atribui ao seu bem pode levar à solução antecipada do conflito de interesses entre particular e Estado, tornando, com isso, a ação administrativa economicamente mais célere e eficiente.

\section{CONCLUSÃO}

Não obstante o intento do presente estudo não tenha consistido em realizar uma defesa absoluta da propriedade privada, sem que se reconhecesse a devida importância do instituto Versão em português recebida em 11/06/2014, aceita em 24/11/2014, e autorizada para publicação em 29/06/2015 


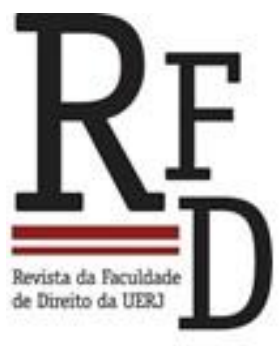

REVISTA DA FACULDADE DE DIREITO DA UERJ- RFD, N. 27, 2015

expropriatório, é inegável que se torna cada vez mais premente repensá-lo em um contexto atual mais amplo, na medida em que o tradicional e autoritário modelo ainda insistentemente adotado pela Administração Pública está em crise, sobretudo em razão da incompatibilidade de importantes normas do regime jurídico vigente com a atual ordem constitucional.

Para tanto, até que sobrevenha novo marco legal regulando adequadamente o instituto, resta ao intérprete buscar, sobretudo através do processo hermenêutico, sua compatibilização com a Constituição - e o vasto rol de direitos individuais por ela assegurados -, rejeitando a mera subsunção das normas vigentes aos fatos expropriatórios.

Como forma, assim, de realização ao máximo dos distintos bens jurídicos em jogo, sustentou-se, no presente estudo, que o uso argumentativo da ponderação, inclusive quando da fixação do justo montante indenizatório, será o mais adequado e seguro para balizar a decisão do administrador público em cada caso concreto. Sua racionalidade, porém, dependerá da adoção de certos parâmetros objetivos, fixados em abstrato, dentre os quais foram destacadas a observância do princípio da isonomia, com enfoque na justa repartição dos encargos e benefícios sociais, e a verificação do grau de eficiência da medida, isto é, sua vantajosidade econômica.

Com a análise proposta pretendeu-se, assim, que, mediante a realização de uma ponderação objetiva entre os interesses envolvidos, sejam alcançadas as finalidades públicas pretendidas, mas que, ao mesmo tempo, não seja gravemente sacrificada a esfera de direitos do indivíduo, cuja tutela dá-se, indiscutivelmente, de forma prioritária em nossa ordem constitucional.

\section{REFERÊNCIAS}

BALDEZ, Paulo de Oliveira Lanzellotti. A imprescindibilidade do uso da Constituição na efetiva e justa solução dos litígios. In: ANDRADE, André Gustavo Corrêa de. (org.). Constitucionalização do Direit: a Constituição como lócus da hermenêutica jurídica. Rio de Janeiro: Lumen Juris, 2003.

BARCELLOS, Ana Paula de. A eficácia jurídica dos princípios constitucionais: o princípio da dignidade da pessoa humana. Rio de Janeiro: Renovar, 2002.

Versão em português recebida em 11/06/2014, aceita em 24/11/2014, e autorizada para publicação em 29/06/2015 


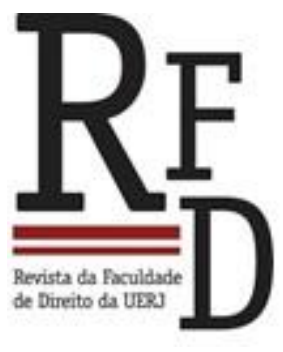

REVISTA DA FACULDADE DE DIREITO DA UERJ- RFD, N. 27, 2015

Alguns parâmetros normativos para a ponderação constitucional. In: BARROSO, Luís Roberto (org.). A nova interpretação constitucional: ponderação, direitos fundamentais e relações privadas. 2. ed. Rio de Janeiro: Renovar, 2006.

BINENBOJM, Gustavo. A Constitucionalização do Direito Administrativo no Brasil: Um inventário de Avanços e Retrocessos. Revista Eletrônica sobre a Reforma do Estado (RERE), Salvador, n. 13, mar./abr./mai. 2008 Disponível em: <http://www.direitodoestado.com/revista/RERE-13-MAR\%C7O-2007-GUSTAVOBINENBOJM.PDF>. Acesso em: 04 jun. 2013.

Uma Teoria do Direito Administrativo: Direitos Fundamentais, Democracia e Constitucionalização. Rio de Janeiro: Renovar, 2008.

ENTERRÍA, Eduardo García de; FERNÁNDEZ, Tomás-Ramón. Curso de Derecho Administrativo. vol. II. Madrid: Editorial Civitas, 1999.

FAUSTO, Boris. História do Brasil. São Paulo: Editora da Universidade de São Paulo, 1995.

FERNANDES, Edésio; ALFONSIN, Betânia. Revisitando o instituto da desapropriação: uma agenda de temas para reflexão. In: FERNANDES, Edésio; ALFONSIN, Betânia (coord.). Revisitando o instituto da desapropriação. Belo Horizonte: Fórum, 2009.

FERRER, de la Cruz J. Princípios de regulación económica en la Unión Europea. Madrid: Instituto de Estúdios Económicos, 2002.

GARNETT. Nicole Stelle. The neglected political economy of eminent domain. Disponível em: <http://papers.ssrn.com/sol3/papers.cfm?abstract_id=875412>. Acesso em: 30 jan. 2012. HADDAD, Emílio; SANTOS, Cacilda Lopes dos. Desapropriação de áreas de interesse ambiental. In: FERNANDES, Edésio; ALFONSIN, Betânia (coord.). Revisitando o instituto da desapropriação. Belo Horizonte: Fórum, 2009.

JUSTEN FILHO, Marçal. Curso de Direito Administrativo. São Paulo: Saraiva, 2005.

LIMA, Paulo de Araújo. Imissão na posse dos bens expropriados. Revista de Direito Administrativo - RDA, Rio de Janeiro, v. 82, p. 395-410, out./dez. 1965.

MELlo, Celso Antonio Bandeira de. Curso de Direito Administrativo. 21. ed. São Paulo: Malheiros, 2006.

MICELI, Thomas J. The economic theory of eminent domain: private property, public use. Cambridge: Cambridge University Press, 2011.

MONTEIRO, Washington de Barros. Curso de Direito Civil: Direito das Coisas. São Paulo: Versão em português recebida em 11/06/2014, aceita em 24/11/2014, e autorizada para publicação em 29/06/2015 


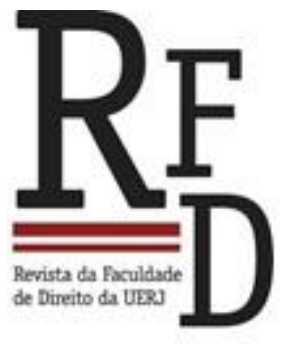

REVISTA DA FACULDADE DE DIREITO DA UERJ- RFD, N. 27, 2015

Saraiva, 1975.

PINILLA PINEDA, Juan Felipe; VILLEGAS DEL CASTILLO, Catalina. Las alternativas del derecho urbano colombiano para la obtención pública de suelo: entre las formas expropriatórias tradicionales y las nuevas formas de gestión del suelo. In: FERNANDES, Edésio; ALFONSIN, Betânia (coord.). Revisitando o instituto da desapropriação. Belo Horizonte: Fórum, 2009.

SALLES, José Carlos de Moraes. A Desapropriação à luz da doutrina e da jurisprudência. 6. ed. rev. atual. e ampl. São Paulo: Revista dos Tribunais, 2009. 